Proceedings

\title{
A Multi-Omics Approach to Interpreting the Influence of Polyphenols in Countering Exercise- Induced Physiological Stress
}

\author{
David C. Nieman * \\ Human Performance Laboratory, Department of Biology, Appalachian State University, North Carolina \\ Research Campus, Kannapolis, NC 28608, USA \\ * Correspondence: niemandc@appstate.edu \\ Published: 30 October 2020
}

\begin{abstract}
Metabolomics, lipidomics, and proteomics provide a systemwide view of the metabolic response to exercise by simultaneously measuring and identifying a large number of small-molecule metabolites, lipids, and proteins. Many of these are involved with immune function and regulation and are sensitive to dietary influences, especially acute carbohydrate ingestion from either sugar beverages or fruits such as bananas. Emerging evidence using large multi-omics data sets supports the combined intake of fruit sugars and phytochemicals by athletes during heavy exertion as an effective strategy to improve metabolic recovery, augment viral defense, and counter postexercise inflammation and immune dysfunction at the cell level. Multi-omics methodologies have given investigators new outcome targets to assess the efficacy of various dietary interventions for physiologically stressed athletes.
\end{abstract}

Publisher's Note: MDPI stays neutral with regard to jurisdictional claims in published maps and institutional affiliations.

(C) 2020 by the authors. Submitted for possible open access publication under the terms and conditions of the Creative Commons Attribution (CC BY) license (http://creativecommons.org/licenses/by/4.0/). 